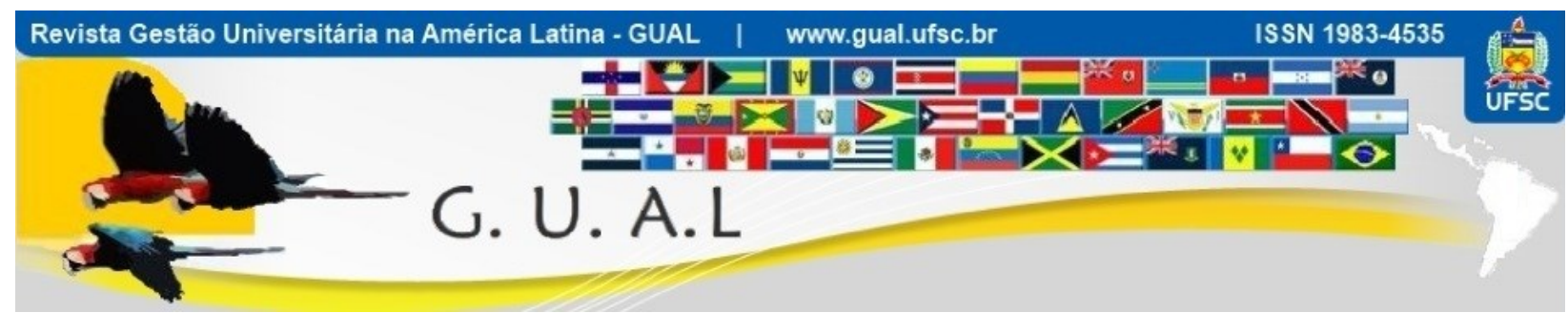

DOI: http://dx.doi.org/10.5007/1983-4535.2020v13n3p119

\title{
INFLUÊNCIAS DO PROGRAMA DE EDUCAÇÃO TUTORIAL (PET) SOBRE A VIDA PROFISSIONAL: UM ESTUDO DE CASO DO PET ADMINISTRAÇÃO DA UFAM
}

\author{
INFLUENCES OF TUTORIAL EDUCATION PROGRAM (PET) IN THE \\ PROFESSIONAL LIFE: A CASE STUDY OF PET ADMINISTRATION OF UFAM
}

\author{
Ana Carolina Cerquinho, Graduada \\ https://orcid.org/0000-0002-6816-9676 \\ anaccerquinho@gmail.com \\ Universidade Federal do Amazonas | Curso de Administração \\ Manaus | Amazonas | Brasil \\ Fabiula Meneguete Vides da Silva, Doutora \\ https://orcid.org/0000-0001-6073-4506 \\ fabiulamv@yahoo.com.br \\ Universidade Federal do Amazonas | Curso de Administração \\ Manaus | Amazonas | Brasil
}

Recebido em 11/dezembro/2019

Aprovado em 04/agosto/2020

Publicado em 01/setembro/2020

Sistema de Avaliação: Double Blind Review

Esta obra está sob uma Licença Creative Commons Atribuição-Uso. 


\title{
RESUMO
}

Com o intuito de melhorar o ensino superior, o Programa de Educação Tutorial (PET) foi criado com base na indissociabilidade do tripé universitário de ensino, pesquisa e extensão. $\mathrm{O}$ estudo apresentado teve como objetivo analisar as influências do PET Administração da UFAM na vida profissional de seus alunos egressos, sendo caracterizado como um estudo de caso. Para a estruturação, foi utilizada a abordagem qualitativa e descritiva, com a realização de entrevistas semiestruturadas. Diante dos resultados adquiridos, foi possível concluir que o PET Administração teve impactos positivos não somente na trajetória profissional dos entrevistados, mas também no seu amadurecimento enquanto indivíduos e acadêmicos, pois sendo um programa completo, proporciona experiências diferentes e atribui conhecimentos novos.

Palavras-chave: Programa de Educação Tutorial. Formação do Administrador. Honors Programs.

\begin{abstract}
With the intent to improve higher education, the Tutorial Education Program (PET) was created on the base of inseparability of the university tripod: education, research and extension. The present study had the main objective to analyze the influences of PET Administration at UFAM on the professional life of their former students, being characterized as a case study. For its structure, qualitative and descriptive approaches were utilized, with semi-structure interviews. Observing the results obtained, it was possible to conclude that the PET Administration had positive impacts not only in the professional trajectory of the interviewed, but also in their growth as individuals and undergraduates. Since it is a complete program, it provides different experiences and contributes to new knowledge.
\end{abstract}

Keywords: Tutorial Education Program. Qualification of Administrators. Honors Programs. 


\section{INTRODUÇÃO}

Originalmente criado pela Coordenação de Aperfeiçoamento de Pessoal de Nível Superior (CAPES) e atualmente administrado pela Secretaria de Educação Superior do Ministério da Educação (SESu/MEC), o Programa de Educação Tutorial (PET) foi implementado nas Instituições de Ensino Superior (IES) em 1979. Com a premissa de auxiliar a melhoria do ensino superior, o PET é fundamentado no princípio de indissociabilidade entre o ensino, a pesquisa e a extensão (BRASIL, 2006), tripé universitário estabelecido no Artigo 207 pela Constituição Federal de 1988 (BRASIL, 1988).

Caracterizado com base nos Honors Programs (CASSIANI; RICCI; SOUZA, 1999), a proposta do PET é agregar mais valor à graduação de ensino superior por meio da exposição de seus discentes a novos conhecimentos e experiências que não seriam plenamente possíveis de se vivenciar dentro da sala de aula por meio de atividades relacionadas ao tripé universitário. Pelo fato de ser um dos poucos programas que engloba, é demonstrado que o PET tem importância no âmbito acadêmico e posteriormente no âmbito profissional, pois seus alunos, durante a graduação, apresentam resultados diferenciados de estudantes de outros tipos de projetos. (SOARES et al., 2010; TOSTA et al., 2006; BRASIL, 2006; BALBACHEVSKY, 1998).

De acordo com o MEC (BRASIL, 2018), atualmente existem 842 grupos PET distribuídos em 121 IES diferentes. Contemplando o PET desde 1988, a Universidade Federal do Amazonas (UFAM) tem 16 grupos PET de diferentes cursos (UFAM, 2019; UA, 1996). $\mathrm{Na}$ área de ensino de Ciências Sociais Aplicadas, apresenta-se o PET Administração, relacionado ao curso de Administração desde janeiro de 1989 (UA, 1996).

Desde sua criação, o PET Administração realiza diversos tipos de projetos acadêmicos, elaborados e realizados pelos discentes participantes do programa, chamados de petianos, com o auxílio do professor tutor, sempre com base na indissociabilidade do ensino, da pesquisa e da extensão (UFAM, 2019; UA, 1996).

Durante os trinta anos de existência na UFAM, observa-se que diversos discentes passaram pelo programa. Assim, a fim de conhecer mais sobre o seu comportamento em sua história e os efeitos que o PET Administração teve na vida de seus ex-alunos, formulou-se o seguinte problema de pesquisa: Quais influências a experiência de fazer parte do PET Administração trouxe para a vida profissional de seus egressos? 
A partir do problema de pesquisa apresentado, este estudo tem como objetivo principal analisar as influências do PET Administração da UFAM na vida profissional de seus egressos. E, para auxílio na obtenção deste, foram elaborados os seguintes objetivos específicos: (a) traçar o perfil dos egressos do PET Administração da UFAM; (b) verificar os impactos que o PET Administração teve na vida pessoal dos egressos; e por fim, (c) identificar, segundo a percepção dos egressos, as contribuições do PET em sua vida profissional.

A relevância deste estudo se apresenta pela necessidade de identificar os impactos que o PET Administração teve na trajetória profissional de seus egressos, visto que, atividades de cunho extracurricular podem trazer uma gama de experiências que não seriam possíveis de se aprender vivenciando apenas a grade curricular comum de um curso de graduação (EIJL et al., 2017; SOARES et al., 2010; BRASIL, 2006; BALBACHEVSKY, 1998). Por sua vez, enquanto há estudos semelhantes acerca do PET nacionalmente, foi observada certa escassez de pesquisas relacionadas aos PETs de Ciências Sociais Aplicadas e de Administração, em especial na UFAM. Portanto, torna-se oportuno analisar o PET Administração da UFAM, podendo esta pesquisa gerar insights, possibilitando uma análise e possível melhoria do programa.

Este artigo está dividido em seis seções, sendo estas: 1. Introdução, onde se apresenta o tema desta pesquisa; 2. Fundamentação Teórica, onde se encontra a estruturação teórica do estudo; 3. Procedimentos Metodológicos, onde será apresentada a metodologia utilizada para a elaboração da coleta e análise de dados; 4. Análise de dados, onde serão apresentados os resultados obtidos na coleta de dados; 5. Considerações Finais, onde será demonstrada as conclusões dos resultados e as sugestões de novos estudos; e 6. Referências, apresentado os autores que serviram de auxílio para a fundamentação deste estudo.

\section{FUNDAMENTAÇÃO TEÓRICA}

\subsection{A EXTRACURRICULARIDADE NO BRASIL: CONTEXTO GERAL E NO CURSO DE ADMINISTRAÇÃO}

Com a crescente preocupação com a qualificação de profissionais aptos para o mercado de trabalho no Brasil, as instituições de ensino superior possuem responsabilidade, como agentes influenciadores, no desenvolvimento dos indivíduos, pois por muito tempo a educação superior brasileira soube apenas transmitir saberes técnicos e teóricos (LIMA, 2007). Assim, torna-se o papel das IES adicionar aos seus cursos outras modalidades fora o 
ensino, como a extensão, que consiste na aplicação de conhecimentos teóricos em ações práticas, e a pesquisa, que caracteriza-se como o desenvolvimento de pesquisas científicas que possam vir a enriquecer os conhecimentos da universidade e sociedade (SOUZA; FERRUGINI; ZAMBALDE, 2017; OLIVEIRA; SANTOS; DIAS, 2016).

Tais atividades, conhecidas como extracurriculares, são associadas a uma graduação de qualidade em aspectos gerais. Isso porque é explicado por autores que o conhecimento não pode estar relacionado apenas com o ensino teórico apresentado em salas de aula. O intuito da participação nessas modalidades tem como objetivo o enriquecendo do crescimento acadêmico, pessoal e profissional dos discentes de graduação, por meio do desenvolvimento de habilidades intrínsecas e auxiliando em torna-los cidadãos mais responsáveis e éticos (EIJL et al., 2017; SOUZA; FERRUGINI; ZAMBALDE, 2017; CASSUNDÉ et al., 2015; PEREIRA et al., 2011; SOARES et al., 2010).

O mercado, por sua vez, demonstra que essas experiências são relevantes. Não é mais exigido dos profissionais, que acabaram de sair do ensino superior, apenas conhecimentos técnicos. Se torna também importante que eles tenham características novas e essenciais, proporcionadas pela participação deles em diversos tipos de atividades, sejam elas estágios, projetos de extensão, programas de iniciação científica e entre outros. (SOUZA; FERRUGINI; ZAMBALDE, 2017; CASSUNDÉ et al., 2015; PEREIRA et al., 2011). Em meio as exigências do mundo externo ao acadêmico, observa-se a importância da aplicabilidade de projetos e programas que envolvam a tríade das universidades (CASSUNDÉ et al., 2015).

Porém, para que haja a busca por novos conhecimentos, nota-se que essa atitude tem que partir dos próprios estudantes de graduação, através de uma análise e compreensão da necessidade de realizar outras atividades, pois a grade curricular apresentada no curso de graduação nem sempre irá abranger todas as exigências para uma formação completa. Como resultado, o discente procura participar de atividades extracurriculares, buscando sanar essas carências (OLIVEIRA; SANTOS; DIAS, 2016; WOLFENSBERGER; EIJL; PILOT, 2012).

A literatura aponta que o processo de aprendizagem não deve ser apenas focado em atividades de ensino tradicionais e que, para se ter uma formação acadêmica de qualidade e consequentemente uma vida profissional melhor, os alunos de graduação devem buscar ter autonomia e proatividade em procurar realizar atividades que envolvam também a pesquisa e 
a extensão. (EIJL et al., 2017; OLIVEIRA; SANTOS; DIAS, 2016; CASSUNDÉ et al., 2015; WONFESBERGER; EIJL; PILOT, 2012).

Nesse contexto, a pesquisa, a extensão e o ensino são apresentados como eixos indissociáveis das instituições de ensino superior, instituídos pelo artigo 207 da Constituição Federal de 1988 (BRASIL, 1988). Nele é disposto que as universidades têm que tratá-los com igual importância, pois estão interligados entre si (MOITA; ANDRADE, 2009). Portanto, a extracurricularidade se torna importante no atendimento dos eixos, os quais são características fundamentais no existir da universidade (PUHL, 2017; CASSUNDÉ et al., 2015).

O ensino da administração no Brasil é datado em 1902, mas, a regulamentação da sua profissão, e, consequentemente, do seu estudo ocorreu apenas sessenta anos mais tarde, por meio da Lei $\mathrm{n}^{\circ} 4.769$ de 9 de setembro de 1965. Em resultado a isso, o acesso ao mercado administrativo se tornou mais voltado para os profissionais diplomados na área (CFA, 2015; MEIRELES et al., 2013; SILVA; FISCHER, 2008; NICOLINI, 2003).

No ano seguinte a regulamentação da profissão, em 1966, o primeiro currículo mínimo do curso de Administração foi instituído. Com a procura por mais profissionais especializados nessa ciência, o curso começou a se expandir por outras partes do território brasileiro (MEIRELES et al., 2013; NICOLINI, 2003).

Devido a sua expansão, surgiram estudos acerca de como a formação do administrador é desenvolvida nas instituições de ensino superior. A justificativa para tal se dá pelo modelo de administradores graduados apresentados ao mercado, que seguem a linha de habilidades unicamente técnicas. Isso porque, segundo estudiosos, anos após a instituição do currículo do curso de administração, este ainda não se desvinculou por completo do de sua criação, em 1966. Esse cenário apresentado, por sua vez, demonstra um problema em frente as exigências que o cenário econômico faz quanto a formação de um administrador (SOUZA; FERRUGINI; ZAMBALDE, 2017; LISBOA, 2015; MEIRELES et al., 2013; SILVA; FISCER, 2008).

Nesse contexto, é evidenciado por estudiosos que a participação de atividades fora da sala de aula são maneiras positivas de amadurecer o capital humano a ser formado nas IES, em especial aos cursos que possibilitam a realização de modalidades extracurriculares. Elas são um dos meios onde há a aplicabilidade e desenvolvimento de habilidades técnicas, sociais e culturais, como o pensamento crítico, o trabalho em equipe, a proatividade, a inovação, comunicação, inteligência emocional, que são características essenciais para a formação de 
um excelente profissional de administração (EIJL et al., 2017; OLIVEIRA; SANTOS; DIAS, 2016; LISBOA, 2015; CASSUNDÉ et al., 2015; PEREIRA et al., 2011).

Dentre as atividades extracurriculares dispostas nas IES brasileiras e no curso de Administração, existe o Programa de Educação Tutorial (PET). Normalmente associado a programas de iniciação científica, é um programa que apresenta como base a indissociabilidade entre o ensino, a pesquisa e a extensão. Portanto, proporciona diferentes experiências, por abranger a tríade universitária (BRASIL, 2008; TOSTA et al., 2006; BALBACHEVSKY, 1998).

\subsection{O PROGRAMA DE EDUCAÇÃO TUTORIAL E O PET ADMINISTRAÇÃO DA UFAM}

Inicialmente nomeado de Programa Especial de Treinamento, o Programa de Educação Tutorial (PET) foi criado em 1979 pela Coordenação de Aperfeiçoamento de Pessoal de Nível Superior (CAPES) para fomentar a formação acadêmica na graduação, preparando seus discentes intelectualmente e profissionalmente e tendo como princípio a prática da indissociabilidade da tríade universitária ensino, pesquisa e extensão (BRASIL, 2008; BRASIL, 2006; UA, 1996). No final do ano de 1999, a responsabilidade sobre o programa passou a ser da Secretaria de Educação Superior do Ministério da Educação SESU/MEC, alocando-o no Departamento de Modernização e Programas da Educação Superior - DEPEM (BRASIL, 2006).

A criação do PET veio por meio da inspiração em uma prática realizada na Faculdade de Ciências Econômicas da Universidade Federal de Minas Gerais de reunir alunos de maior destaque e formar grupos de estudos, nos Honors Programs, programas internacionais que tem como objetivo auxiliar discentes interessados a se desenvolverem por meio de atividades e outros programas extracurriculares (ALENCAR et al., 2014; WOLFENSBERGER; EIJL; PILOT, 2012; CASSIANI; RICCI; SOUZA, 1999).

Historicamente, o PET foi implementado inicialmente em poucas universidades, sendo ampliado para o resto do país após estudos realizados internamente pela CAPES demonstrarem resultados positivos quanto a efetividade do programa (ALENCAR et al., 2014; UA, 1996). Assim, o PET passou por diversos procedimentos de aperfeiçoamento e consolidação desde sua criação até os dias atuais (ALENCAR et al., 2014; TOSTA et al., 2006; BALBACHEVSKY, 1998). 
Após a sua passagem para a SESu/MEC em 1999, o programa passou por dificuldade quanto a como procederia. Em 2005, por meio do DEPEM, medidas foram tomadas para que houvesse o aprimoramento do PET, mudando a sua nomenclatura de Programa Especial de Treinamento para Programa de Educação Tutorial, e propondo a sua regulamentação por meio da Lei $\mathrm{n}^{\circ} 11.180 / 05$ e das Portarias $\mathrm{n}^{\circ} 3.385 / 05$ e $\mathrm{n}^{\circ}$ 1.632/06 (ALENCAR et al., 2014; BRASIL, 2008; BRASIL, 2006), fortalecendo a criação de um novo Manual de Orientações Básicas do PET. Essa dinamização resultou na reafirmação da presença do PET no meio universitário como um programa intrínseco, único e diretamente relacionado com a graduação (BRASIL, 2008).

O Programa de Educação Tutorial (PET) foi implementado na Universidade Federal do Amazonas (UFAM) no ano de 1988, ainda sob o nome de Programa Especial de Treinamento, por intermédio da Pró-Reitoria de Pesquisa e Pós-Graduação que apresentou o projeto para os cursos existentes no ano. Destes, apenas dois cursos se interessaram pela iniciativa: o curso de Comunicação Social e o curso de Administração. O PET Administração iniciou suas atividades em janeiro de 1989, sendo alocado no departamento de Administração da Faculdade de Estudos Sociais (FES) na UFAM (UA, 1996).

O objetivo do PET Administração é oferecer uma graduação de melhor qualidade aos seus alunos, sejam eles bolsistas ou não bolsistas, buscando desenvolvê-los enquanto indivíduos e coletivo, tornando-os assim profissionais responsáveis e críticos quanto ao futuro de sua profissão e da pesquisa. Visa também auxiliar no desenvolvimento de uma melhora no curso de Administração da UFAM, através de suas atividades (UA, 1996).

Quanto as suas competências, o PET Administração realiza atividades que visam interligar o ensino, a pesquisa e a extensão desde sua criação em 1989 (UA, 1996), até os tempos atuais. Para tal, são realizados planejamentos participativos, com a presença de todos os petianos e o professor tutor, buscando organizar quais atividades o grupo realiza enquanto coletivo (UA, 1996).

Dentre as atividades realizadas, podem ser descritas leituras de artigos, realização de eventos e palestras, atividades em grupo e individuais, pesquisas acadêmicas. Esta descrição das atividades do PET visa sempre estar de acordo com o seu Manual de Orientações Básicas e com a sua finalidade enquanto programa acadêmico, aprimorando o desenvolvimento de alunos internos ao programa e externos a ele (BRASIL, 2006; UA, 1996). 


\section{PROCEDIMENTOS METODOLÓGICOS}

Este estudo teve como objetivo analisar as influências que o PET de Administração da UFAM teve na vida de seus egressos. Dada essa característica, a abordagem escolhida foi a pesquisa qualitativa que, por utilizar instrumentos não estatísticos, tem como pretensão apresentar uma realidade particular, utilizando-se de um aprofundamento a fenômenos que não podem ser reduzidos a apenas variáveis (RICHARDSON et al., 2007; MINAYO, 2002). Justifica-se tal aplicabilidade pois, por existir no âmbito universitário há 30 anos e ser o único PET pertence a área de Ciências Sociais Aplicadas na UFAM, observa-se a necessidade de uma pesquisa mais aprofundada e detalhada acerca da experiência do programa.

Assim, quanto aos meios, trata-se de um estudo de caso (VERGARA, 2003), pois tem como principal objeto de pesquisa o PET Administração. Quanto os fins, este estudo se caracteriza como descritivo (GIL, 2008; VERGARA, 2003), pois tem como objetivo analisar e descrever a percepção que os alunos egressos do PET Administração tiveram acerca das influências que o programa acadêmico teve na sua vida profissional.

Os critérios para a participação na pesquisa foram egressos do curso de Administração e do PET Administração, formados até o primeiro semestre de 2019 e que estivessem trabalhando ou que já tivessem alguma experiência no mercado de trabalho. No total, entrouse em contato com 35 egressos, recebendo a resposta de 13 inicialmente. Realizou-se um préteste da primeira versão do roteiro de entrevista e se verificou a necessidade de reformulação. Com a nova elaboração, foi acrescentada a disponibilização de um termo de consentimento livre e esclarecido, apresentado no início de cada entrevista, onde havia a explicação do estudo e da total liberdade de participação ou não do entrevistado, além de afirmar o sigilo de informações pessoais compartilhadas. Posteriormente, na realização das entrevistas houve uma saturação de dados (MINAYO, 2017), fazendo com que o universo estudado fosse de nove egressos.

A coleta de dados foi feita através de entrevistas semiestruturadas, possibilitando que houvesse uma flexibilidade e uma conversa mais fluída entre o pesquisador e os entrevistados. Foram elaboradas 27 perguntas com base nos objetivos desta pesquisa, incluindo as questões sobre o perfil dos entrevistados (gênero, faixa etária, etc.). Para a obtenção de candidatos à entrevista, foi-se utilizava a técnica de Snowball que tem como base a ideia de que um entrevistado indica outro e assim subsequentemente (GOODMAN, 1961). Isso se deu pelo fato de que, apesar de ser um programa antigo na instituição, não se tem dados dos egressos 


\section{INFLUÊNCIAS DO PROGRAMA DE EDUCAÇÃO TUTORIAL (PET) SOBRE A VIDA PROFISSIONAL: \\ UM ESTUDO DE CASO DO PET ADMINISTRAÇÃO DA UFAM \\ DOI: http://dx.doi.org/10.5007/1983-4535.2020v13n3p119}

no departamento responsável na UFAM. Assim, buscou-se pelos contatos de ex-petianos através de professores e alunos do departamento de Administração. O período de realização da coleta de dados se deu entre os dias 02 de outubro de 2019 a 11 de outubro de 2019.

Para a análise de dados foi utilizado o método de Análise de Conteúdo descrito por Bardin (2016). O objetivo da utilização desse método se dá pela sua forma de tratamento de dados, visto que auxiliou na identificação e análise do que estava sendo respondido pelos entrevistados sobre o PET Administração.

\section{ANÁLISE DE DADOS}

O universo estudado para esta pesquisa abrange nove egressos do PET Administração, tendo os seus perfis dispostos no quadro a seguir.

Quadro 1 Perfil dos entrevistados

\begin{tabular}{|c|c|l|c|c|l|l|}
\hline Entrevistados & Gênero & \multicolumn{1}{|c|}{ Faixa etária } & $\begin{array}{c}\text { Tempo } \\
\text { no PET }\end{array}$ & $\begin{array}{c}\text { Ano de } \\
\text { graduação }\end{array}$ & $\begin{array}{c}\text { Formação } \\
\text { atual }\end{array}$ & \multicolumn{1}{|c|}{$\begin{array}{c}\text { Formação } \\
\text { pretendida }\end{array}$} \\
\hline P1 & Fem. & Acima de 30 anos & 3 anos & 1998 & Doutorado & Pós-doutorado \\
\hline P2 & Masc. & Entre 21 e 26 anos & 2 anos & 2019 & Bacharelado & Mestrado \\
\hline P3 & Fem. & Acima de 30 anos & $\begin{array}{c}3 \text { anos } \\
1 \text { anos e } \\
8 \text { meses }\end{array}$ & 2008 & Mestrado & Doutorado \\
\hline P4 & Fem. & Entre 21 e 26 anos & Especialização & Mestrado \\
\hline P5 & Fem. & Entre 21 e 26 anos & 2 anos & 2018 & $\begin{array}{l}\text { Concluindo } \\
\text { Especialização }\end{array}$ & Doutorado \\
\hline P6 & Fem. & Entre 27 e 30 anos & 2 anos & 2014 & $\begin{array}{l}\text { Concluindo } \\
\text { MBA }\end{array}$ & Pós-doutorado \\
\hline P7 & Fem. & Entre 21 e 26 anos & 2 anos & 2019 & Bacharelado & MBA \\
\hline P8 & Fem. & Acima de 30 anos & $\begin{array}{l}2 \text { anos e } \\
3 \text { meses }\end{array}$ & 2013 & $\begin{array}{l}\text { Concluindo } \\
\text { Mestrado }\end{array}$ & Doutorado \\
\hline P9 & Fem. & Entre 27 e 30 anos & 2 anos & 2014 & $\begin{array}{l}\text { Concluindo } \\
\text { Especialização }\end{array}$ & Doutorado \\
\hline
\end{tabular}

Fonte: Elaborado pelas autoras (2019).

Nesta pesquisa, os entrevistados foram questionados sobre o seu nível de formação atual bem como o nível de formação pretendido e qual era a justificativa para tal. Os fragmentos de P1 e P9 explicam que o desejo de ter um nível acima da graduação aconteceu por conta da sua participação em atividades proporcionadas pelo PET Administração.

P1: "Eu tinha parado para analisar isso (sobre querer o nível pretendido) e penso que tem a ver comigo e com o PET [...]. Eu adorava o que eu fazia no PET e ali já me encaminhou totalmente. É tanto que eu terminei a faculdade, fiz a prova do ANPAD e já fui direto para o mestrado."

P9: "Quando eu sai do PET, até pela influência de pesquisa e tudo, eu pensava um pouco em seguir a carreira acadêmica, como professor. Atualmente eu não tenho tanto esse objetivo, porém doutorado é algo que auxilia na carreira [...] então seria algo a agregar." 
Soares et al. (2010) demonstram que as experiências no PET trazem como resultado a necessidade da busca por uma melhor qualificação, por meio de cursos de pós-graduação. Os demais entrevistados não entraram em tantos detalhes, mas demonstraram que a sua pretensão não parte de um despreparo profissional, e sim de uma vontade de ter mais conhecimento e de crescimento na carreira, como apresentam P8 e P6.

P8: "Pra questão da minha melhora profissional, né, porque é um mestrado na área que eu trabalho."

P6: “Tenho pretensões pra doutorado, pós-doutorado. É um nível que nos dá bastante conhecimento, você consegue entender mais abrangente a questão da sua área, você conhece outras pessoas, você tem outras oportunidades e conhecimento nunca é demais, é sempre bom."

Além do perfil apresentado, indagou-se sobre o perfil de comportamento dos indivíduos entrevistados. Oliveira, Santos e Dias (2016) discutem que há um processo de desenvolvimento de autonomia dos discentes, seja antes ou durante a graduação, pela busca de conhecimentos práticos e que, por vezes devido à falta desses na grade curricular, há necessidade de buscar experiências complementares. Em seus discursos, os entrevistados P3, P6 e P2 mostraram que a vontade de realizar atividades extracurriculares dentro da universidade é comum entre eles.

P3: "O meu objetivo foi a conexão com a universidade, assim, ter dedicação exclusiva no curso. [...] Esse foi o motivo, né, a gente sair das atividades somente da sala de aula, ter contato com a comunidade, com a extensão, com a pesquisa, então tudo isso era muito bom."

P6: "Então, eu entrei no PET porque ele nos dava acesso a vários projetos, né, [...] era o meu sonho estudar na UFAM, então eu disse que quando eu conseguisse, eu ia querer viver a essência da faculdade. Ai quando eu entrei, eu descobri o PET, que a gente tinha tantas oportunidades de participar de projetos, né, de fazer eventos, de viver aquilo num contexto de aprendizado. Achei tão interessante."

P2: "Meu objetivo era ter uma vivência maior da faculdade, ter um contato maior com os professores, ter um contato maior com os programas de ensino, pesquisa e extensão, contato com outros cursos e não só ter aulas, mas um plus na universidade, ter um diferencial até."

Diante do descrito anteriormente pelos entrevistados, Oliveira, Santos e Dias (2016) explicam que a vontade de participar de atividades extracurriculares parte de um amadurecimento de autonomia e é normalmente associada a alunos concluintes e não a calouros. Está justificativa dos autores não foi percebida na pesquisa com os nove egressos 
entrevistados, já que se interessaram e participaram do Programa assim que adentraram a Universidade, no segundo ou terceiro semestre do curso.

Partindo do pressuposto de que o PET Administração teve impactos no desenvolvimento pessoal de seus egressos, observou-se por meio das falas dos entrevistados que as experiências vividas enquanto petianos influenciaram positivamente. Esta afirmação explica-se porque, segundo Cassundé et al. (2015) e Brasil (2008), ao participar de atividades assim, os alunos entram em contato com experiências diferentes e tem que aprender a lidar com isso externa e internamente, como é apresentado nos fragmentos de P4, P5 e P7.

P4: “[...] Eu era muito sensível, não podiam falar assim que eu errei que eu chorava muito e o PET me ajudou muito, né, nesse sentido, a amadurecer. Outra coisa também era que na época eu era, assim, muito de escutar, nunca fui de falar o que eu sentia, o que queria, as minhas ideias e eu consegui melhor muito isso lá no PET, então realmente foi muito pro lado pessoal."

P5: "Desenvolveu muito a empatia, né, porque nós trabalhávamos também a questão da extensão, coisas fora da universidade, atividades com a comunidade, né. Isso desenvolve muito a nossa questão humana também, de querer que outras pessoas façam parte do ambiente universitário. [...] Contribuiu pra que a gente abrisse a nossa visão de mundo, a visão de perspectivas diferentes das nossas."

P7: “[...] Essa é a questão que eu falo, eu melhorei muito como pessoa, na maneira de me relacionar. Eu não estaria aqui contigo hoje, talvez, se eu não tivesse melhorado algumas coisas que eu achava ruins em mim antes do PET. [...] A possibilidade de eu poder melhorar essas coisas, a minha insegurança, a minha dificuldade de falar com outras pessoas, de expor minhas ideias, porque eu sabia que eu ia precisar futuramente, eu enxerguei no PET."

Assim como houve crescimento pessoal, os egressos atribuíam também ao PET influências quanto ao seu desenvolvimento profissional. Porém, nos discursos dos entrevistados, percebe-se íntima ligação entre as duas habilidades. Eijl et al. (2017), Oliveira, Santos e Dias (2016), Lisboa (2015), Cassundé et al. (2015) e Pereira et al. (2011) discorrem que existem características necessárias para que os estudantes de graduação tenham sucesso em sua vida profissional. Tais aptidões gerais são relacionadas diretamente com conhecimentos e atitudes, que podem ser adquiridas por meio da extracurricularidade. Os autores sugerem que as duas formas, profissional e pessoal, andam lado a lado, como confirma P6.

P6: "O PET pra mim enquanto acadêmica foi uma oportunidade de viver na prática aquilo que eu iria encontrar no mercado de trabalho em todos os sentidos, não só na questão de você se posicionar como profissional, mas também como pessoa, com valores. Você tem que saber alinhar quem é você enquanto profissional e quem é você enquanto pessoas e essas duas ideias 
precisam caminhar juntas pra você ser honesto, pra você ter liderança, pra você saber lidar com as pessoas, pra saber lidar consigo mesmo. Então o PET foi isso, assim, na minha percepção."

Desta forma, dentre as características apresentadas pelos autores, algumas das habilidades importantes foram citadas pelos egressos. Para eles, o PET Administração possibilitou não somente o desenvolvimento técnico, ao poderem aplicar o conhecimento teórico em atividades práticas, mas também o desenvolvimento da inteligência emocional, como mostram os fragmentos de P6 e P9.

P6: "Uma das coisas que eu mais tenho, assim, que eu desenvolvi e aprendi a dar atenção lá no PET é a questão da inteligência emocional, então isso foi chave pra mim, ter assim essa experiência. [...] Querendo ou não, a gente é treinamento mais pra inteligência técnica, né, você saber os termos, você saber o que tem que fazer, pra onde ir e a gente esquece que nós somos humanos, que nós temos emoções e que se você não souber lidar com as suas emoções, você não vai conseguir atingir as metas que você precisa atingir no mundo profissional."

P9: "[...] A questão da inteligência emocional era um tópico que o tutor trabalhava muito com a gente, você saber controlar suas emoções, seus sentimentos. [...] Foi algo que me marcou."

Ao PET Administração também foi creditada, pelas falas dos entrevistados P4, P1 e P5, a oportunidade de aprender a trabalhar em equipe, respeitando a individualidade do outro e compreendendo que o grupo deveria estar trabalhando em sintonia.

P4: "Sempre foi muito trabalho em equipe e isso é muito importante, né, então nunca foi nada sozinho. Então, se saia algo errado, era a equipe que estava errada."

P1: "Acho que a questão mesmo que ficou muito foi essa questão de trabalho em equipe [...], um trabalho totalmente horizontal, porque fora o tutor, nós não tínhamos um líder entre nós. Tínhamos que trabalhar em equipe totalmente de igual pra igual, então isso era muito bom."

P5: "Na minha vida profissional, eu acho que a parte do trabalho em equipe, né. Tudo a gente tinha que fazer planejado, a gente tinha que se organizar, organizar nossos tempos, nossos horários, ver o que cada um ia fazer [...] então eu levo até hoje."

Alencar et al. (2014), Brasil (2008) e Brasil (2006) discorrem que o PET tem como um dos seus objetivos o desenvolvimento de um apoio mútuo entre os petianos, tornando-os capazes de amadurecerem a partir da reflexão e da aprendizagem coletiva.

Outro ponto reforçado pelos fragmentos de P8, P9 e P3 é a questão da proatividade. Wolfensberger, Eijl e Pilot (2012) argumentam que o resultado da vontade de participar de atividades extracurriculares, como os Honors Programs, resulta no recebimento de novas 
oportunidades e novos problemas a serem enfrentados. De acordo com os entrevistados, haviam necessidades do PET Administração que os direcionavam para proatividade no momento de realizar as suas atividades.

P8: "Uma coisa foi muito bem reforçada na gestão do tutor, essa questão da proatividade. Ele orientava, mas as coisas só saíram por causa que a gente que meteu a mão na massa [...], a gente ir atrás de fazer as coisas e não esperar ninguém dar ordem."

P9: "De você utilizar a criatividade e a inovação, os recursos são escassos então a gente tem que tá sempre se virando com pouca coisa pra fazer acontecer, correr atrás de parcerias, fazer elaboração de projetos, organização de eventos. [...] Eu destacaria essa parte desse interesse por buscar as coisas, não ficar esperando as coisas caírem de bandeja na sua mão, mas ir atrás, fazer acontecer."

P3: "A gente passou por alguns problemas, né, o tutor na época tava bem doente, teve uma época que ele ficou realmente ausente e nós que tocamos o PET. Então, a gente tinha o compromisso mesmo, acho que um com o outro, de que o grupo não podia parar."

Para que todas as habilidades pudessem ser desenvolvidas, os entrevistados argumentam que o auxílio do professor tutor e dos colegas petianos foram essenciais. Tosta et al. (2006) e Balbachevsky (1998) salientam que alguns aspectos de sucesso do programa não podem ser atribuídos a estruturação do projeto do PET em si, mas sim de fatores diversos, como por exemplo a convivência com colegas de outros períodos, pessoas externas à IES e a presença do professor tutor, auxiliando por meio da elaboração de estratégias e ações. Logo, a efetividade do PET não estaria garantida apenas com o seu desenho institucional, mas com a forma que o grupo se organiza e trabalha, como demonstram os fragmentos de P3 e P6.

P3: “A gente tem um tutor, né, que é um professor e ele nos orienta em todos os sentidos, então é ali que a gente tem aquele contato próximo. É ele que tira todas as nossas dúvidas. [...] A gente tem essa oportunidade no PET, na sala de aula não, você tá ali com o professor pra tirar dúvidas daquela matéria, mas questões da vida profissional e acadêmica, a gente não tem, então no PET a gente tinha essa oportunidade."

P6: "Nossa, o PET me ensinou tantas coisas, não só em relação a vida profissional em si mas também a questão das relações humanas. Não é fácil você lidar com pessoas diferentes, vocês têm ali uma meta a atingir e são pessoas diferentes que precisam trabalhar junto pra fazer. Na época eu peguei uma turma muito boa, mas tinham algumas pessoas difíceis de se relacionar e eu pude aprender a lidar com isso também. Então era um desafio constate, e eu pude ver também conforme eu ia participando mais do PET, que eu ia ganhando mais aprendizados em todos os aspectos." 
Em consequência a essas habilidades desenvolvidas, foi analisado que na maioria dos casos, o PET Administração auxiliou também na vida acadêmica, como demonstram os discursos de P5 e P1. Brasil (2006) explana que para um aluno ser parte do PET, tem que vir dele sempre essa busca de conhecimento e de se melhorar enquanto pessoal, profissional e acadêmico.

P5: "Na vida acadêmica, a gente sempre era cobrado. Sei lá, uma nota baixa ou alguma coisa, 'tu não é do PET?'. Em relação a vida acadêmica, eu acredito que me fez melhorar mais porque a gente tinha mais, tinha que estar no PET a tarde, a gente tinha, né, o momento de estudar."

P1: "Eu acho que tantos atributos, assim, comportamentais, eu pude amadurecer e desenvolver bastante quanto a questão do estudo, porque nós tínhamos uma casa muito maior de leitura, pesquisa, de palestras, então eu acho que o PET contribuiu nesse desenvolvimento."

Dentro do contexto profissional, questionou-se aos entrevistados sobre suas aspirações de carreira enquanto graduandos, bem como se as participações no PET Administração contribuíram para esse almejo. Os fragmentos de P4 e P3 explicitam que, ainda como petianos, já identificavam um futuro profissional.

P4: “O PET era um miniempresinha, porque de qualquer forma tinha lá o seu setor de marketing, de financeiro, o administrativo. [...] Ele não tinha ligação com empresa júnior, mas tinha um arzinho assim de empresa e eu gostava muito daquilo. [...] Falava 'nossa, imagina se fosse uma empresa?'. Então, desde o PET, eu tive mais certeza (de empreender) [...], foi o início ali, sabe?"

P3: "Eu sempre optei pelo serviço público, eu sempre quis seguir essa linha, pela estabilidade, então eu tava perseguindo mesmo o cargo de analista nos concursos. Ai depois veio a oportunidade de docência e eu fique 'ah, legal, eu gosto'. No PET, a gente acaba exercendo isso, fizemos trabalhos em escolas de educação básica, então a gente tinha esse contato com a sala de aula e isso também despertou. Então era assim, eu tinha essa intenção de entrar no serviço público [...] e aí depois do mestrado, né, a gente tem como ingressar na docência e eu persegui essa linha da docência e hoje estou aqui."

Uma explicação para isso se dá por Brasil (2008), que apresenta em sua literatura que o PET, por ser um programa de aprendizagem tutorial, tem características únicas e, portanto, tem a capacidade de proporcionar experiências de diversos tipos, seja para a carreira acadêmica ou para o mercado externo. O programa tem a capacidade, portanto, de agregar conhecimentos distintos aos seus discentes e fazer com que eles tenham visão mais ampla sobre a vida profissional. 
$\mathrm{O}$ fato de o PET ser fomentado na base da indissociabilidade de ensino, pesquisa e extensão o torna um Programa completo, que abrange diversos tipos de atividades, como afirma Brasil (2008). Na visão dos egressos P8, P2, P4 e P7, participar do PET fez com que eles tivessem a oportunidade de vivenciar a Universidade como um todo.

P8: "Eu vivi a universidade por inteiro, que eu fiz extensão, pesquisa. [...] O PET me permitiu conhecer a universidade. Porque, enquanto muitos alunos apenas vêm pra aula, eles saem logo em seguida e não vivem a faculdade e assim, é uma experiência riquíssima."

P2: "É justamente essa questão de você não ficar preso a teoria, entendeu? Você tem uma visão de mundo melhor quando você participa de algo assim, você tem uma certa bagagem. [...] Com o PET, você já tinha um pouco mais de prática. Mesmo que de forma pequena, eu já tinha uma certa aplicação daquilo que eu aprendia na sala, então isso me ajudou."

P4: "Eu acho que o PET teve muito esse impacto assim de me transformar, sabe? De eu conseguir ter uma experiência a mais, né, pessoalmente como estudante e depois como profissional. Realmente é algo muito bom."

P7: "A gente vive a universidade de uma forma muito mais ampla quando a gente tá no PET, porque tu conhece professores, tu sabe de PIBIC, PACE. Eu sabia que eu podia fazer e tem muita gente que tá aqui que não sabe. Então, tu tá no PET, eu acho que tu tem muito mais informação pra passar e pra crescer mesmo aqui dentro."

Relacionando-se aos fatores citados, foi apresentada uma hipótese para os entrevistados: se na percepção deles, não participar de atividades extracurriculares, em especial o PET Administração, teria afetado a sua inserção no mercado. Dos nove discursos analisados, todos entram em comum acordo que a realização das atividades os preparou de alguma forma para o seu futuro dentro do mercado de trabalho, fosse parcial ou totalmente. As evidências disso podem ser vistas pelos discursos de P1, P4, P5 e P9.

P1: "Eu penso que eu teria ido pra um estágio e possivelmente teria entrado já no ambiente organizacional e não tivesse seguido carreira acadêmica. [...] Eu penso que se não tivesse sido o PET, a minha trajetória seria diferente." P4: "Olha, eu realmente seria uma pessoa, como eu posso dizer... fazendo um monte de pós-graduação, um monte de curso pra me sentir preparada, pra não ficar com medo de nada. Com certeza estaria trabalhando pra alguma empresa, tentando me complementar de alguma forma, né, que realmente, muitas vezes eu parei pra pensar 'cara, se eu tivesse feito nada disso, cara..."”.

P5: “Acredito que sim, por um lado sim. Porque assim, muitos dos colegas viam o PET como algo assim de gente que não tinha muito o que fazer, por exemplo, 'ah, eu trabalho, né, então eu já tenho uma técnica', alguma coisa assim e tal, mas o PET abriu outros horizontes que talvez essa pessoa que trabalha não tenha tido, entendeu?"

P9: "Acredito que seria mais difícil, pra conseguir um emprego, como eu falei, o PET abriu portas. Foi através de uma indicação que eu consegui uma 
entrevista e vim a ser selecionado. Eu fiz uma entrevista de estágio e não passei, eu fiz outra depois pra efetivo e acabei passando. Inclusive, era numa área relacionada a pesquisa que eu realizava no artigo, né, então eu acredito que facilitou muito por estar mais próximo do mercado e pelos conhecimentos que eu aprendi."

Estudos como o de Eijl et al (2017), Cassundé et al. (2015), Wolfensberger, Eijl e Pilot (2012) e Balbachevsky (1998) evidenciam que a participação em programas de atividades extracurriculares beneficia intrinsecamente os discentes. Os resultados apresentados anteriormente pelos entrevistados afirmam que houve o desenvolvimento de habilidades técnicas e práticas, mas também emocionais e intelectuais, que auxiliam em suas vidas pessoais e profissionais.

Aos entrevistados, também foi questionado sobre os pontos negativos do Programa, em relação a questões profissionais. Os resultados encontrados citam especialmente as experiências que os egressos tiveram enquanto graduandos, como a falta de recursos financeiros, a falta de apoio da IES e a falta de parcerias com instituições externas a Universidade. Os discursos de P3, P6 e P5 demonstram esses fatores.

P3: "Assim, o que a gente era bastante penalizado era por falta de recursos, né, pra você ter ideia, quando a gente viajava e tinha um congresso, a gente vendia as coisas na UFAM. A gente vendia bolo, a gente vendia as coisas pra ter dinheiro, então, a gente não tinha esse suporte financeiro. [...] Acho que foi um ponto bem negativo, porque limita, né, a nossa participação, a gente tinha que correr atrás mesmo, tirar do nosso bolso, então a gente sofria bastante com a falta de recursos."

P6: "Olha, algumas questões burocráticas [...]. A gente poderia ter tido mais apoio da universidade com um todo pra desenvolver mais esse projeto. A gente conseguiu fazer muitas coisas interessantes, mas era sempre lutando muito, batendo de porta em porta das empresas pra conseguir, o que também não foi ruim porque ajudou a gente a entender mais né, $[\ldots]$ mas eu acho que o ponto negativo que eu diria é que a burocracia, a falta de estrutura pra apoiar mais esses projetos, faz com que a gente perca muito tempo. Ao invés de estar produzindo coisas, fazendo projetos mais interessantes, dando frutos através disso, a gente ainda tem que buscar muito a base."

P5: "Em questão de estágios e outras aspirações, fica por conta do aluno e aí você resolve sair do PET porque arranjou um estágio ou até um trabalho. Se a universidade e o PET tivessem acordos de cooperação, acordos de capacidade técnica com outras instituições e até mesmo órgãos, né, seria mais facilitado, porque você tem o aluno, você tem ali o capital intelectual e você precisa desenvolver. Algumas questões do mercado de trabalho são desenvolvidas lá, né, o PET e a universidade ainda ficam mais na teoria, apesar do PET ser um pouco mais que só a sala de aula."

A literatura Brasil (2008), Tosta et al. (2006) e Brasil (2006) demonstram que o PET é um Programa rico e que atende ao que se propõe. Mas, como também afirma Balbachevsky 
(1998), para que haja efetividade e sucesso, ele depende do seu capital humano e da realização de estratégias que auxiliem nesse processo de desenvolvimento de atividades e crescimentos diversos de seus integrantes.

\section{CONSIDERAÇÕES FINAIS}

Este artigo teve como finalidade analisar as influências do PET Administração da UFAM na vida profissional de seus egressos. Para tanto, foi necessário se utilizar de caminhos para atingir esse objetivo, como traçar o perfil dos egressos do PET Administração da UFAM, verificar os impactos que o PET Administração teve na vida pessoal dos egressos e identificar, segundo a percepção dos egressos, as contribuições do PET em sua vida profissional.

A delimitação do perfil de cada egresso entrevistado foi demonstrada nos resultados. A partir dessas informações, teve-se a verificação de que os nove egressos entraram no PET Administração nos primeiros períodos do curso e que permaneceram no programa por mais de um ano e, diante disso, houve uma indagação sobre o tipo de comportamento aqueles egressos tinham enquanto pessoas. Suas respostas entraram em comum acordo com a literatura, pois os egressos se demonstraram pessoas interessadas em participar de atividades fora da sala de aula, as chamadas extracurriculares, e viram no PET Administração a oportunidade de desenvolver e aplicar diversos tipos de habilidades.

Em aspectos relacionados a vida pessoal, o PET Administração serviu como uma ponte para o desenvolvimento dos egressos enquanto pessoas. Os discursos são claros ao apontar os pontos positivos do programa quanto a esse quesito, pois eles tiveram a capacidade de amadurecer a partir das experiências vividas em grupo. E, como relatado pelos egressos, o PET foi uma de suas primeiras experiências profissionais, tornando o programa responsável por parte do amadurecimento deles enquanto acadêmicos, pessoas e profissionais.

Foi possível notar também pelos discursos que, em suas percepções, o PET Administração contribuiu para a vida profissional, pois os entrevistados indicaram ao menos um ponto de impacto que o PET teve em suas trajetórias, fosse em atitudes, percepções, ações ou até mesmo escolhas profissionais.

Diante das constatações dos egressos, porém, fica claro que essas habilidades não andam separadas. Verifica-se que, para que houvesse um desenvolvimento profissional, era necessário que também houvesse um desenvolvimento pessoal e intelectual dos egressos, pois 
são competências que se interligam. A demonstração disso pode ser vista por meio das habilidades desenvolvidas ressaltadas pelos egressos, como a inteligência emocional, o trabalho em grupo e a proatividade. São aspectos que precisaram de um amadurecimento de compreensão da sua importância, tanto na vida profissional quanto na vida pessoal. Em resultado a isso, por estarem tendo essas experiências enquanto graduandos, a vida acadêmica se configura de maneira diferenciada. $\mathrm{O}$ fato de serem alunos do PET fazia com que eles tivessem certa visibilidade dentro do curso de Administração pelos colegas e pelos professores, pressionando-os a demonstrarem o seu diferencial enquanto alunos, pois esse era o esperado dos petianos.

Para que ocorressem esses desenvolvimentos, os entrevistados atribuíram sua evolução às vivências em grupo, aos próprios colegas petianos e ao professor tutor. Analisou-se que, para ter efetividade nas propostas descritas do programa, era necessário que o capital humano presente no PET criasse estratégias, agissem em prol das atividades e necessidades do programa, pois apenas a estruturação do PET na teoria não era o suficiente para a sua sobrevivência. Isso, porém, também criou situações complicadas, na visão dos entrevistados. Os pontos negativos ao programa que foram apresentados pelos egressos são, em sua maioria, sobre a falta de apoio externo, fosse por meio de recursos financeiros, pelas burocracias que eram impostas pela IES ou pela falta de parcerias e ações que conectariam o aluno com o mercado de trabalho. Nota-se que a funcionalidade do programa é resultado do trabalho de quem vive o contexto do PET, pois ele compreende a necessidade da existência do programa, mas as dificuldades fazem com que muitos processos simples se tornem complexos.

Mas, para além das habilidades desenvolvidas, das responsabilidades adquiridas e problemas enfrentados, os entrevistados apontaram o fato de que eles conheceram a universidade e de como isso foi importante para a sua formação, pois, mesmo que não viessem a aplicar tudo que aprenderam, vivenciar a universidade de uma forma mais ampla e por inteiro é uma experiência riquíssima. E, por apresentar a indissociabilidade do ensino, da pesquisa e da extensão na sua base, o PET é apresentado como um programa acadêmico completo e rico que possibilita ao aluno que participa dele experiências e conhecimentos novos que agregam valor e possibilita a eles uma graduação de qualidade e, posteriormente, uma vida pessoal e profissional melhor.

Estudos sobre o PET são relevantes, pois é um programa diferenciado, onde muitos alunos passaram e ainda irão passar. Logo, para estudos futuros, sugere-se realizar uma 
pesquisa semelhante a essa em outros PETs existentes que ainda não tiveram a possibilidade de ter uma análise das suas influências e impactos em seus egressos. Além deste, também é sugerida uma análise aprofundada dos impactos na formação acadêmica com alunos bolsistas e não bolsistas do PET Administração da UFAM e outros PETs; pesquisas com foco nos tutores sobre a percepção deles acerca do programa e a percepção de alunos que não participam PET sobre os efeitos positivos e negativos do programa.

\section{REFERÊNCIAS}

ALENCAR, M. M. T. et al. O Programa de Educação Tutorial na Faculdade de Serviço Social da Universidade do Estado do Rio de Janeiro. In: VELOSO, R. dos S. et al. (Orgs.).

Trajetória da Faculdade de Serviço Social da UERJ: 70 anos de história. Rio de Janeiro: EdUERJ, 2014. Disponível em: < http://www.fss.uerj.br/downloads/Colet $\%$ C3\%A2nea\%2070\%20ANOS\%20FSS/15.pdf>. Acesso em: 28 set. 2019.

BALBACHEVSKY, E. O Programa Especial de Treinamento - PET/CAPES - e a Graduação no Ensino Superior Brasileiro. InfoCAPES - Boletim Informativo da CAPES, v. 6, n. 2, p. 7-24, Brasília, abr/jun. 1998.

BARDIN, L. Análise de conteúdo. São Paulo: Edições 70, 2016.

BRASIL. Constituição da República Federativa do Brasil. Senado: Brasília, 1988. Disponível em $<$ https://www.senado.leg.br/atividade/const/con1988/con1988_18.02.2016/art_207_.asp $>$. Acesso em 20 set 2019.

. Ministério da Educação. Apresentação PET. 2018. Disponível em: < http://portal.mec.gov.br/pet/>. Acesso em: 01 abril 2019.

. Ministério da Educação. Manual de Orientações Básicas do Programa de

Educação Tutorial. Brasília: Dezembro, 2006. Disponível em

$<$ http://portal.mec.gov.br/index.php?option $=$ com docman\&view $=$ download\&alias $=338$ manualorientabasicas\&category slug=pet-programa-de-educacao-tutorial\&Itemid $=30192>$. Acesso em 28 abril 2019.

. Ministério da Educação. PET: Programa de Educação Tutorial: estratégia para o desenvolvimento da graduação. Brasília: Ministério da Educação, 2008.

CASSIANI, S. H. B.; RICCI, W. Z.; SOUZA, C. R. A experiência do Programa Especial de Treinamento na educação de estudantes de Graduação em Enfermagem. Revista Latinoamericana de Enfermagem, Ribeirão Preto, v. 6, n. 1, p. 45-63, 1999. Disponível em: < http://www.scielo.br/pdf/rlae/v6n1/13922.pdf >. Acesso em: 28 set. 2019. 
CASSUNDÉ, F. R. de S. A. et al. Participar ou não participar, eis a questão! Um estudo sobre o engajamento dos estudantes de Administração em atividades extracurriculares. Id online Revista de Psicologia, Juazeiro do Norte, v. 9, n. 26, p. 42-56, 2015.

CFA. Conselho Federal de Administração. 50 anos que fizeram história: jubileu de ouro: Sistema CFA/CRAs / Conselho Federal de Administração. - Brasília, DF, 2015. $2^{\mathrm{a}}$ Edição.

EIJL, P. V. et al. Honors programs as forerunner for $21^{\text {st }}$ century skills? Journal of the European Honors Council, v. 1, n. 2, p. 1-15, Zwolle, jun. 2017.

GIL, A. C. Métodos e técnicas de pesquisa social. 6. ed. São Paulo: Atlas, 2008.

GOODMAN, L. A. Snowball Sampling. The Annals of Mathematical Statistics, Michigan, v. 32, n. 1, p. 148-170, 1961. Disponível em: $<$ http://www.jstor.org/stable/2237615 $>$. Acesso em: 01 out. 2019.

LIMA, M. C. O. O Sentido da Educação no Contexto da Sociedade Pós-Moderna. Revista ANGRAD, v. 8, n. 1, p 109-128, 2007.

LISBOA, T. C. A Formação do Administrador no Brasil: Competências e habilidades. Lisboa, Portugal, 2015.

MEIRELES, F. R. S. et al. Uma avaliação dos conhecimentos necessários, adquiridos e utilizados pelos egressos do curso de administração. Revista Gestão Universitária na América Latina - GUAL, Florianópolis, v. 6, n. 3, p. 190-209, set. 2013. Disponível em: $<$ https://periodicos.ufsc.br/index.php/gual/article/view/1983-4535.2013v6n3p190>. Acesso em: 13 maio 2019.

MINAYO, M. C. S. Amostragem e saturação em pesquisa qualitativa: consensos e controvérsias. Revista Pesquisa Qualitativa, São Paulo, v. 5, n. 7, p. 01-12, 2017.

Ciência, Técnica e Arte: O Desafio da Pesquisa Social. In: DESLANDES, S.F. et al. (Org.) Pesquisa social: teoria, método e criatividade. 21. ed. Petrópolis: Vozes, 2002.

MOITA, F. M. G. da S. C.; ANDRADE, F. C. B. de. Ensino-pesquisa-extensão: um exercício de indissociabilidade na pós-graduação. Revista Brasileira de Educação, Rio de Janeiro, v. 14, n. 41, p. 269-280, aug. 2009. Disponível em:

$<$ http://www.scielo.br/scielo.php?script $=$ sci arttext\&pid $=\mathrm{S} 1413-$

24782009000200006\&lng=en\&nrm=iso >. Acesso em: 29 maio 2019.

NICOLINI, A. Qual será o futuro das fábricas de administradores? Revista de Administração de Empresas, São Paulo, v. 43, n.2, p.44-54, jun. 2003. Disponível em: $<$ http://www.scielo.br/scielo.php?script $=$ sci arttext\&pid $=$ S003475902003000200003\&lng=en\&nrm=iso $>$ Acesso em: 29 maio 2019.

OLIVEIRA, C. T.; SANTOS, A. S.; DIAS, A. C. G. Percepções de Estudantes Universitários sobre a Realização de Atividades Extracurriculares na Graduação. Revista Psicologia:

Ciência e Profissão, Brasília, v. 36, n. 4, p. 864-876, dec. 2016. Disponível em: 
$<$ http://www.scielo.br/scielo.php?script $=$ sci arttext\&pid $=$ S141498932016000400864\&lng=en\&nrm=iso>. Acesso em: 30 maio 2019.

PEREIRA, A. K. et al. A importância das atividades extracurriculares universitárias para o alcance dos objetivos profissionais dos alunos de administração da Universidade Federal de Santa Catarina. Revista Gestão Universitária na América Latina - GUAL, Florianópolis, p. 163-194, jun. 2011.

PUHL, M. J. O conhecimento e o princípio da indissociabilidade entre ensino, pesquisa e extensão. Revista HISTEDBR On-Line, v. 16, n. 69, p. 222-232, fev. 2017.

RICHARDSON, R. J. et al. Pesquisa social: métodos e técnicas. 3. ed. rev. ampl. São Paulo: Atlas, 2007.

SILVA, M. R. da; FISCHER, T. Ensino de Administração: um estudo da trajetória curricular de cursos de graduação. In: ENCONTRO DA ASSOCIAÇÃO NACIONAL DE PÓSGRADUAÇÃO E PESQUISA EM ADMINISTRAÇÃO, 32., 2008, Rio de Janeiro. Anais eletrônicos... Rio de Janeiro: AnPAD, 2008.

SOARES, F. F. et al. Impacto do Programa de Educação Tutorial da Faculdade de Odontologia da Universidade Federal da Bahia na formação profissional dos seus exbolsistas. RPG - Revista de Pós-Graduação, São Paulo, v. 17, n. 3, set. 2010. Disponível em

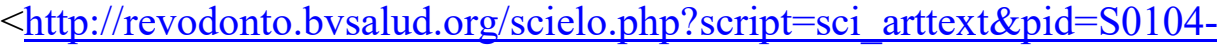

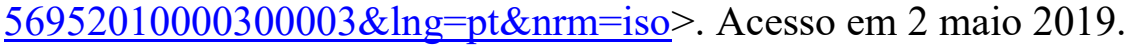

SOUZA, D. L. de; FERRUGINI, L.; ZAMBALDE, A. L. Formação do administrador: uma análise sobre o desenvolvimento de competências no ensino superior. Revista Gestão Universitária na América Latina - GUAL, Florianópolis, v. 10, n.1, p. 150-171, jan. 2017.

TOSTA, R. M. et al. Programa de educação tutorial (PET): uma alternativa para a melhoria da graduação. Psicologia para América Latina, México, n. 8, nov. 2006. Disponível em $<$ http://pepsic.bvsalud.org/scielo.php?script $=$ sci arttext\&pid $=\mathrm{S} 1870-$ $\underline{350 X 2006000400004 \& \operatorname{lng}=\mathrm{en} \& \mathrm{nrm}=\mathrm{iso}}>$. Acesso em 10 maio 2019.

UA. Universidade do Amazonas. Encontros de Grupos PET - Programa Especial de Treinamento. Manaus: Universidade do Amazonas, 1996.

UFAM. Universidade Federal do Amazonas. Grupos PET Promovem Feira. UFAM, Manaus, 2019. Disponível em $<$ https://ufam.edu.br/noticias-bloco-esquerdo/9820-grupos-petpromovem-feira $>$. Acesso em 30 maio 2019.

VERGARA, S.C. Projetos e relatórios de Pesquisa em Administração. $7^{\mathrm{a}}$ ed. São Paulo: Atlas, 2003.

WOLFENSBERGER, M.V.C.; EIJL, P.V.; PILOT, A. Laboratories for Educational Innovation: Honors Programs in the Netherlands. Journal of the National Collegiate Honors Council, v. 13, n. 2, p. 149-170, 2012. Disponível em: < https://core.ac.uk/download/pdf/159430394.pdf>. Acesso em: 28 set. 2019. 